\title{
Are allergic reactions to indocyanine green really that uncommon? A single institution experiences
}

\author{
Andrea Papadia ${ }^{1 *}$, Maria Luisa Gasparri ${ }^{1,2}$ and Michael D Mueller ${ }^{1}$ \\ ${ }^{1}$ Department of Obstetrics and Gynecology, University Hospital of Berne and University of Berne, Berne, Switzerland \\ ${ }^{2}$ Department of Gynecology and Obstetrics, "Sapienza" University of Rome, Rome, Italy
}

\section{Introduction}

Indocyanine Green (ICG) is a compound that was developed in the 1950 s by Kodak. It was meant to be employed in the photography. In 1956 its use via intravenous injection was approved in the medical field. Since then, it has mainly been employed in ophthalmology where it is used for Fluor angiographies. Since a few years, ICG has successfully been employed in Sentinel Lymph Node (SLN) mapping [1]. After an off label interstitial injection of the tracer, a fluorescent signal can be elicited with a dedicated device that emits light in the Near Infrared (NIR) wavelength. This allows for an easy identification of the SLN. In gynecologic oncology this tracer has proven to be at least equivalent to the combination of technetium-99m Tc-99m and blue dyes as far as detection rates goes [2-6]. ICG seems to perform better in obese patients and is user friendlier as it does not require a preoperative intracervical injection as is the case with Tc- $99 \mathrm{~m}$. This ease of use is perceived by the patients as a better quality of delivered care [7]. Furthermore, its toxicity profile seems to compare well with that of the other tracers that are commonly employed for SLN mapping [8]. The information on the toxicity profile of the ICG mainly relates to the ophthalmologic literature, where this compound has been employed for a long interval of time. ICG is considered to be a safe drug with an estimated rate of allergic reactions of $0.05 \%$ [9].

\section{Case report}

We report a case of a 65-year-old woman affected by a carcinosarcoma that was clinically and radiologically confined to the uterus who underwent an anaphylactic reaction to ICG. The patient was planned to undergo a laparoscopic hysterectomy, bilateral salpingo-oophorectomy, SLN biopsy followed by a pelvic and paraaortic lymphadenectomy. After a general anesthesia was obtained, a laparoscopy was performed. After having obtained a pneumoperitoneum, having inserted the optic trocar and three ancillary trocars and having explored the abdominal organs to rule out extrauterine spread of the disease, $8 \mathrm{ml}$ of an ICG solution $(5 \mathrm{mg} / \mathrm{ml})$ were injected interstitially in the cervix as previously described [1]. The solution of ICG was obtained through the suspension of one vial of 25 mg ICG powder $\left(\right.$ Pulsion $^{\circledR}$ ) with $5 \mathrm{ml}$ of sterile water. Approximately one minute after ICG injection, the patient collapsed secondary to an anaphylaxis and had to be resuscitated with CPR, $2.2 \mathrm{mg}$ adrenalin, 2 mg Tavgyl ${ }^{\circledR}$ and $125 \mathrm{mg}$ Solu-Medrol ${ }^{\circledR}$. Eventually, the cardiovascular system recovered, and the patient was transferred to the ICU. The patient recovered completely without any signs of neurological damage. The patient had a slight reaction to ICG in the prick test. Esmeron ${ }^{\circledR}$, fentanyl, propofol, latex and chlorhexidine all tested negative. After having recovered, allergic test were performed to identify the agent that was responsible for the anaphylaxis. Based on these results and on the timing of the allergic reaction ICG was considered to be responsible for the allergic reaction. The patient war re-operated on ten days later. A laparoscopy with total hysterectomy, bilateral salpingo-oophorectomy, pelvic and paraaortic lymphadenecomy was performed without complications.

\section{Discussion}

In our cohort of 234 patients ( 58 cervical cancer patients and 176 endometrial cancer patients) who have been subjected to interstitial injection of ICG for SLN mapping since 2013 this is the only case of allergic reaction that we have recorded, accounting for an incidence of severe allergic reactions of $0.4 \%$. No other adverse effects of any grade have been recorded in our cohort of patients. In the past few years several series on patients undergoing ICG SLN mapping for various oncologic diagnoses have been published and no severe reactions have been reported so far. Although there is a tendency to underreport negative results and complications in the literature, it is plausible that the real incidence of an anaphylactic reaction to ICG is lower that what we have recorded. Still, severe allergic reaction is much more common to blue dyes as compared to ICG with a reported rate that varies between $0.7 \%$ and $1.9 \%$ [10-14].

Our patient was injected with a relatively high dose of ICG. Different centers have been using different doses and concentrations of ICG for SLN mapping which are typically lower than the one adopted at our institution, ranging from 0,5 to $2,5 \mathrm{mg} / \mathrm{ml}[2,15]$. It is unlikely that the higher dose of ICG injected is responsible for the recorded allergic reaction.

An anaphylactic shock is a dramatic life-threatening event that can occur with virtually any medication. Depending on the mechanism of action, allergic reactions are divided into four types:

- Type I: IgE mediated. This type of allergic reaction is characterized by a rapid response that occurs in minutes. Free antigens cross link the IgE on mast cells and basophils causing a release of vasoactive biomolecules. This type of reaction can be responsible for anaphylactic reactions.

Correspondence to: Andrea Papadia, Department of Obstetrics and Gynecology, University Hospital of Berne and University of Berne, Effingerstrasse 102, 3010 Bern, Switzerland, Tel. +41 3163212 01; Fax. +41 3163212 05; E-mail: andrea. papadia@insel.ch

Received: October 15, 2017; Accepted: October 24, 2017; Published: October 27,2017 
- Type II: IgM or IgG mediated. Ig G or Ig M antibodies bind to cell surface antigens, with subsequent complement fixation. This type of reaction is responsible for, among others, autoimmune hemolytic anemia.

- Type III: IgG mediated. Circulating antigen-antibody immune complexes deposit in postcapillary venules, with subsequent complement fixation. This type of reaction is responsible for the lupus erythematosus systemic.

- Type IV: T-cell mediated. Helper T cells are activated by an antigen presenting cell. At the subsequent exposure, the memory $\mathrm{T}$ helper cells will activate macrophages and cause an inflammatory response. This type of reaction is responsible, among others, for contact dermatitis.

Based on their severity allergic reactions are classified in three grades:

- Grade 1: urticaria or blue hives, Pruritus, and/or a generalized rash;

- Grade 2: transient hypotension (systolic blood pressure $\geq 70 \mathrm{~mm}$ $\mathrm{Hg}$ ) not requiring vasopressors;

- Grade 3: hypotension (systolic blood pressure $<70 \mathrm{~mm} \mathrm{Hg}$ ) requiring vasopressor support. Grade 3 reactions are life threatening and typically require an ICU admission.

ICG contains sodium iodide and, according to the manufacturer, it should be used with caution in patients who have a history of allergy to iodides because of the risk of anaphylaxis. Since iodine is a chemical element that is an essential component of the human body, some authors suggest that ICG can be safely employed in patients with iodine allergy since a type-I allergic reaction (antibody mediated, responsible for anaphylactic shock) can virtually not occur [16]. Still, type I reactions may occur to other excipients of ICG.

It is crucial to be aware of the potential allergic reactions that may occur after the administration of ICG and the anesthesiologist should always be notified when ICG is injected. Overall ICG remains a very safe product that performs better than the other conventional tracers (such as Tc-99m and blue dyes alone or in combination) when adopted for the SLN mapping in gynecologic oncology [2-6,8]. Although adverse reactions resulting from an intravenous or an interstitial injection of ICG are expected to be the same, since ICG has only been approved by FDA for intravenous injection, it is crucial to inform the patients undergoing SLN mapping on its off-label use as adverse reactions may otherwise lead to unpleasant medico-legal consequences.

\section{References}

1. Papadia A, Imboden S, Siegenthaler F, Gasparri ML, et al. (2016) Laparoscopic Indocyanine Green Sentinel Lymph Node Mapping in Endometrial Cancer. Ann Surg Oncol 23: 2206-2211. [Crossref]

2. Papadia A, Zapardiel I, Bussi B, Ghezzi F, Ceccaroni M, et al. (2017) Sentinel lymph node mapping in patients with stage I endometrial carcinoma: a focus on bilateral mapping identification by comparing radiotracer $\mathrm{Tc}^{\mathrm{m}} 9^{\mathrm{m}}$ with blue dye versus indocyanine green fluorescent dye. J Cancer Res Clin Oncol 143: 475-480. [Crossref]

3. Ruscito I, Gasparri ML, Braicu EI, Bellati F, Raio L, et al. (2016) Sentinel Node Mapping in Cervical and Endometrial Cancer: Indocyanine Green Versus Other Conventional Dyes-A Meta-Analysis. Ann Surg Oncol 23: 3749-3756. [Crossref]

4. Imboden S, Papadia A, Nauwerk M, McKinnon B, Kollmann Z, et al. (2015) A Comparison of Radiocolloid and Indocyanine Green Fluorescence Imaging, Sentinel Lymph Node Mapping in Patients with Cervical Cancer Undergoing Laparoscopic Surgery. Ann Surg Oncol 22: 4198-203. [Crossref]

5. Buda A, Papadia A, Zapardiel I, Vizza E, Ghezzi F, et al. (2016) From Conventional Radiotracer Tc-99(m) with Blue Dye to Indocyanine Green Fluorescence: A Comparison of Methods Towards Optimization of Sentinel Lymph Node Mapping in Early Stage Cervical Cancer for a Laparoscopic Approach. Ann Surg Oncol 23: 29592965. [Crossref]

6. Di Martino G, Crivellaro C, De Ponti E, Bussi B, Papadia A, et al. (2017) Indocyanine Green Versus Radiotracer \pm Blue Dye for Sentinel Lymph Node Mapping in $>$ Stage IB1 Cervical Cancer (> 2 cm). J Minim Invasive Gynecol 24: 954-959. [Crossref]

7. Buda A, Elisei F, Palazzi S, De Ponti E, et al. (2016) Quality of Care for Cervical and Endometrial Cancer Patients: The Impact of Different Techniques of Sentinel Lymph Node Mapping on Patient Satisfaction. Ann Surg Oncol 23: 2975-2981. [Crossref]

8. Papadia A, Gasparri ML, Buda A, Mueller MD (2017) Sentinel lymph node mapping in endometrial cancer: comparison of fluorescence dye with traditional radiocolloid and blue. J Cancer Res Clin Oncol. [Crossref]

9. Hope-Ross M, Yannuzzi LA, Gragoudas ES, Guyer DR, Slakter JS, et al. (1994) Adverse reactions due to indocyanine green. Ophthalmology 101: 529-533. [Crossref]

10. Albo D, Wayne JD, Hunt KK, Rahlfs TF, Singletary SE, et al. (2001) Anaphylactic reactions to isosulfan blue dye during sentinel lymph node biopsy for breast cancer. $\mathrm{Am}$ J Surg 182: 393-398. [Crossref]

11. Cimmino VM, Brown AC, Szocik JF, Pass HA, Moline S, et al. (2001) Allergic reactions to isosulfan blue during sentinel node biopsy--a common event. Surgery 130: 439-442. [Crossref]

12. Hirsch JI, Tisnado J, Cho SR, Beachley MC (1982) Use of isosulfan blue for identification of lymphatic vessels: experimental and clinical evaluation. AJR Am J Roentgenol 139: 1061-1064. [Crossref]

13. Leong SP, Donegan E, Heffernon W, Dean S, Katz JA (2000) Adverse reactions to isosulfan blue during selective sentinel lymph node dissection in melanoma. Ann Surg Oncol 7: 361-366. [Crossref]

14. Montgomery LL, Thorne AC, Van Zee KJ, Fey J, Heerdt AS, et al. (2002) Isosulfan blue dye reactions during sentinel lymph node mapping for breast cancer. Anesth Analg 95: 385-388. [Crossref]

15. Ditto A, Martinelli F, Bogani G, Papadia A, Lorusso D, et al. (2015) Sentinel node mapping using hysteroscopic injection of indocyanine green and laparoscopic nearinfrared fluorescence imaging in endometrial cancer staging. J Minim Invasive Gynecol 22: 132-133. [Crossref]

16. Krohne TU, Allam JP, Novak N, Holz FG (2016) [“Iodine allergy": A medical myth with risks for the ophthalmological patient]. Ophthalmologe 113: 1023-1028. [Crossref]

Copyright: (C2017 Papadia A. This is an open-access article distributed under the terms of the Creative Commons Attribution License, which permits unrestricted use, distribution, and reproduction in any medium, provided the original author and source are credited. 